\title{
VOLTAGE QUALITY IDENTIFICATION AND MITIGATION USING SIMPLE PI BASED ABC CONTROLLED DVR IN DISTRIBUTION SYSTEM
}

\author{
DR. S. VIJAYALAXMI ${ }^{1}$, A. BALAJI ${ }^{2}$, B. PHANIRANGARAJA ${ }^{3} \&$ K. PRIYADARISHNI ${ }^{4}$ \\ ${ }^{1}$ Associate Professor, Usha Rama college of Engineering and Technology, Telaprolu, Andhra Pradesh, India \\ ${ }^{2,3,4}$ Assistant Professor, Usha Rama college of Engineering and Technology, Telaprolu, Andhra Pradesh, India
}

\begin{abstract}
The most noticeable topic for Electrical Engineering is power quality in recent years. Power quality problem is an occurrence manifested as a nonstandard voltage, current or frequency. Utility distribution networks, sensitive industrial loads andcritical commercial operations suffer from various types of outages and service interruption can cost significant financial losses. One of the major problems dealt hereis the voltage sag and swell. The fast development in power electronics technology has made it possible to mitigate power quality problems. The work presented in this paper is confined to voltage quality identification and mitigation for sag and swell. The work carried out concentrates on the development of simple RMS algorithms for identification of voltage quality problems and development ofsimplified suitable devices for mitigation of voltage sag and swell. Many of the suitable devices such as D-STATCOM, UPQC and DVR are available to mitigate voltage sag and swell problems. Among these, Dynamic Voltage Restorer (DVR) canprovide the most commercial solution to mitigate voltage sag by injecting voltage aswell as power into the system. Dynamic Voltage Restorer is a series connected powe relectronics based device that can quickly mitigate the voltage sag and swell in the system and restore the load voltage. Energy storage device used in this work isBattery for DVR and it is responsible for supplying active power needed during voltage sag and swell. simpleabc control algorithm which is to utilize the error signal to control the triggering of the switches of an inverter using Pulse Width Modulation (PWM) technique. Modeling and simulation of proposed DVR control is implemented in MATLAB /SIMULINKsoftware and results are presented.
\end{abstract}

KEYWORDS: Voltage Quality, Waveform Distortion, Voltage Disturbances and Dynamic Voltage Restorer

Received: May 15, 2020; Accepted: Jun 05, 2020; Published: Jul 29, 2020; Paper Id.: IJMPERDJUN2020514

\section{INTRODUCTION}

Delivering good quality of power to the loads is the main agenda for distribution system. But maintaining power quality is not so easy due to the load variations in the system. Sag and swell are the main factors that affect power quality and there is an essential need to identify them using suitable methods which are simple and accurate. Voltage sag and swell identification depends on the calculation of the true RMS of the voltagesignal.This paper provides a brief simple PI based 'abc' frame theory. The control strategy is implemented to improve the performance and efficiency of DVR. PI based new simple abc theory is used toovercome drawbacks of SRF theory[1]. There is no need for transformation and actualvoltages (Vabc(act)) are compared with reference voltages (Vabc(ref)). The gains ofPI controller Kp and Ki are tuned by trial and error method. PI based simple abccontrol theory has less processing time, compact in size and available in low cost ascompared to SRF controller.The power quality problems defined, how the voltage waveform of system being distorted. There are various problems occurred like transients, short duration variations (sags, swells and interruption), long duration variations (sustained 
interruptions, under voltages, over voltages), voltage imbalance, waveform distortion ext. from those, they are three main Power Quality problems have been encountered to the customers are voltage sags, Swell and transients[2,3]. This work includes voltage sag/swell occurred in distribution system is automatically identified by using RMS algorithm and DVR with simple PI based ABC control has to be implemented for mitigating the voltage quality problems. Any lag in the process of injecting the voltage into line would be harmful to sensitive loadsconnected to system that are vulnerable to voltage sag and swell[4].

\section{2: RMS ALGORITHM FOR VOLTAGE QUALITY IDENTIFICATION}

A simple algorithm called RMS algorithm is developed to detect the sag/swellin the system. This algorithm is very simple for implementation of discrete signalscomputation and effective for identification of voltage quality disturbances. Rootmean square equation is used for calculating voltage magnitude of the system. Basedon the magnitude one can differentiate sag and swell problems. Identified voltagefrom the algorithm is exported to Matlab file.RMS (voltage or current) is a quantity commonly used in power systems as aneasy way of accessing and describing power system phenomena. The RMS value canbe computed each time a new sample is obtained but generally these values areupdated each cycle or half cycle. If the RMS values are updated every time a newsample is obtained, then the calculated RMS series is called continuous. If theupdating of rms is done with a certain time interval, then the obtained RMS is called discrete. As long as the voltage is sinusoidal, it does not matter whether RMS voltage, fundamental voltage, or peak voltage is used to obtain the sag and swell magnitude.

The flow chart for identification of voltage sag and swell in power distributionsystem by using RMS algorithm is shown in fig. 1 and its each block is explained below.

Compared with FFT, wavelet methods the RMS algorithm is very simple algorithm for implementation, of root mean square equation is used for calculating voltage magnitude based on the magnitude one can differentiate sag and swell problems.

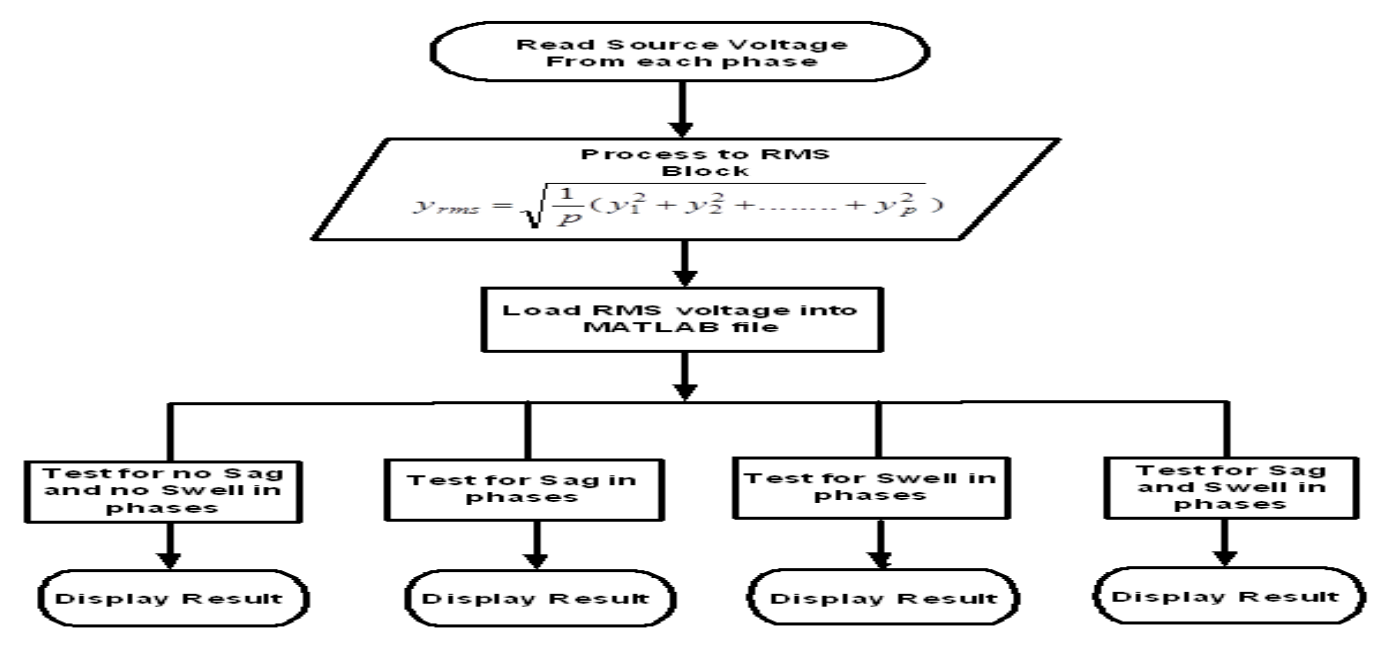

Figure 1: RMS Algorithm for identification of voltage sag and swell

Read Source Voltage from each Phase: The sag/swell detection process initially starts from the measurement unit connected to the power system network. This measurement unit is connected to each phase individually. The measured signals are sent for further processing of theidentification. 
Process to RMS Block: The RMS algorithm is used to break down a signal into its various magnitude components. According to RMS definition the RMS voltage of a set of values (or continuous -time waveform) is the square root of the arithmetic mean of the squares of the values, or the square of the function that defines the continuous waveform.

In the case of a set of $n$ values $\left\{\mathrm{y}_{1}, \mathrm{y}_{2}, \mathrm{y}_{3}, \ldots \mathrm{y}_{\mathrm{n}}\right\}$ the rms

$$
Y_{r m s}=\sqrt{1 / N\left(y_{1}^{2}\right.}+y_{2}^{2}+\cdots y_{n}^{2}
$$

According to definition the RMS voltage over one cycle is done by using the discrete integral. $\mathrm{N}$ is the sample per cycle of the fundamental, $\mathrm{y}_{\mathrm{n}}$ is the nth sample of the recorded voltage waveform. Voltage signals are recorded as sampled points in time and the RMS value of a sampled time-domain signal iscalculated

$$
Y_{r m s}=\sqrt{1 / N \sum_{n=1}^{N} y_{n}^{2}}
$$

Where $\mathrm{N}$ is the number of samples per cycle and $\mathrm{y}_{\mathrm{n}}$ is the magnitudes of sampled signal.

The RMS value of continuous signal in interval $d_{1}<t<d_{2}$

$$
y_{r m s}=\sqrt{\frac{1}{d_{2}-d_{1}}} \int_{d_{1}}^{d_{2}}[y(t)]^{2} d t
$$

Load RMS Voltage into Matlab File: The identified voltage magnitude from the RMS block is given to the MATLAB file for comparison of voltage magnitudes with the given reference signal. In MATLAB file multiple conditional operators have been included for identification of type of faultie L-G, LL-G and LLL-G and occurrence time.

Test for No Sag and Swell in Phases: If there is no deviation in RMS voltage of phases, it indicates that there is no sag and swell in phases.

Test for Sag: In the MATLAB file, the identified voltages are compared with the specified reference voltage with the use of logical operators. If the identified voltage is less than the specified voltage, it is referred as sag. From the standard definition of voltage sag, it is described as voltage value from 0.9 pu to $0.1 \mathrm{pu}$ of nominal value for duration from 0.5 cycle to1min.

Test for Swell: In the MATLAB file, the identified voltages are compared with the specified reference voltage. If the identified voltage is greater it is considered as swell. From the standard definition it is described as voltage valuerangingfrom 1.1 p.u to 1.8 p.u of nominal value for a duration from 0.5 cycle to 1 mint.

Test for Sag and Swell in Phases: This block identifies presence of voltage sag and swell simultaneously in differentphases.

Display Result: The end of the identification process is displaying the results. These results are further utilized for mitigation of voltage sag and swell.

\section{DVR WITH PI BASED SIMPLE ABC CONTROL}

In this section DVR with PI based simple abc theory is discussed. Fig.2. shows the control block diagram for DVR with PI based simple abc control. PI based new simplified abc theory is used to overcome drawbacks of SRF theory. There is no 
need for transformation and actual voltages ( $\mathrm{Vabc}(\mathrm{act}))$ are compared with reference voltages ( $\mathrm{Vabc}(\mathrm{ref})$ ). The gains of PI controller $\left(\mathrm{k}_{\mathrm{p}}=10\right)$, and $\left(\mathrm{k}_{\mathrm{i}}=1\right)$, are tuned by trial and error method. PI based simple abc control theory has less processing time, compact in size and available in less cost compared to SRF controller

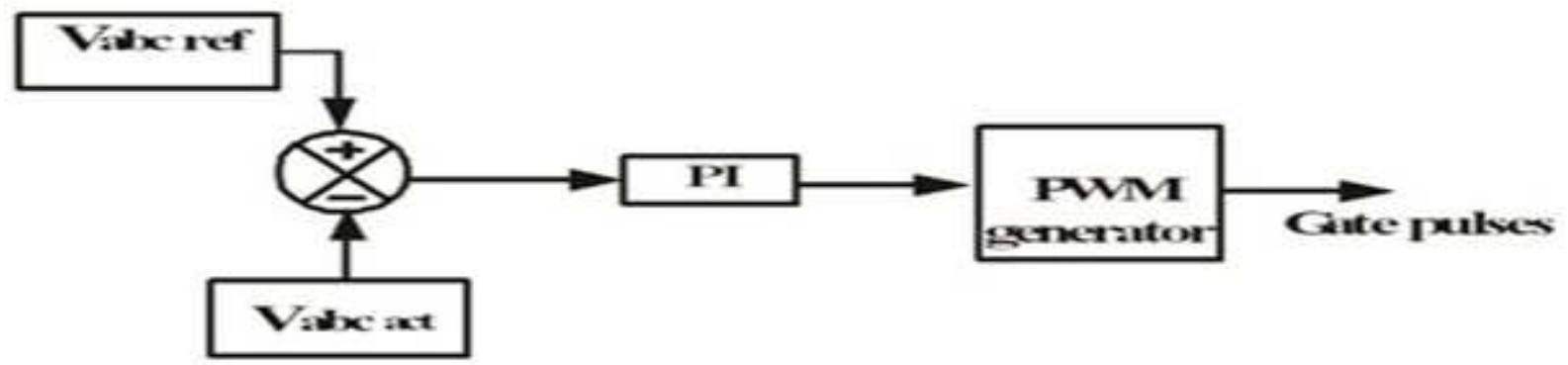

Figure 2: DVR Control Block Diagram of PI based Simple abc control

\section{DVR WITH PROPOSED SIMPLIFIED ABC ALGORITHM}

It is seen from fig.3.that the source voltage $\mathrm{V}_{\text {cabcis }}$ sensed at PCC and given as an input to the Phase Locked Loop (PLL) block. The PLL block generates three phase components displaced $120^{\circ}$ (degree) from each other and these are multiplied with $\mathrm{V}_{\text {ref, }}$ to get three phase reference values ( $\mathrm{V}_{\text {abcref }}$ ). These are expressed mathematically asfollows

$$
\begin{aligned}
& V_{\text {aref }}=V_{\text {ref }} \sin w t \\
& V_{\text {aref }}=V_{\text {ref }} \sin \left(w t-\frac{2 \pi}{3}\right) \quad V_{\text {aref }}=V_{\text {ref }} \sin \left(w t+\frac{2 \pi}{3}\right)
\end{aligned}
$$

The above equations are compared with actual three phase values $\mathrm{V}_{\text {cabc(act). }}$. The error generated is given as an input to the PI controller. The PI controller output is given as an input to the PWM generator and from that the gate pulses are generated for the inverter to inject or absorbed voltage at PCC in series to the distribution line through injecting transformer. When the voltage sag or swell has occurred, it is sensed and proper gain setting is made in the controller and based on this control the PWM generator generates the required pulses to the inverter. From the inverter, it is fed to the injection transformer feeds to the necessary voltage. The major job of controller in the DVR is to identify the voltage sag and swell occurrences, calculate the compensating voltage, to produce trigger pulses of PWM inverter and stop the trigger pulses when the occurrence ispassed.

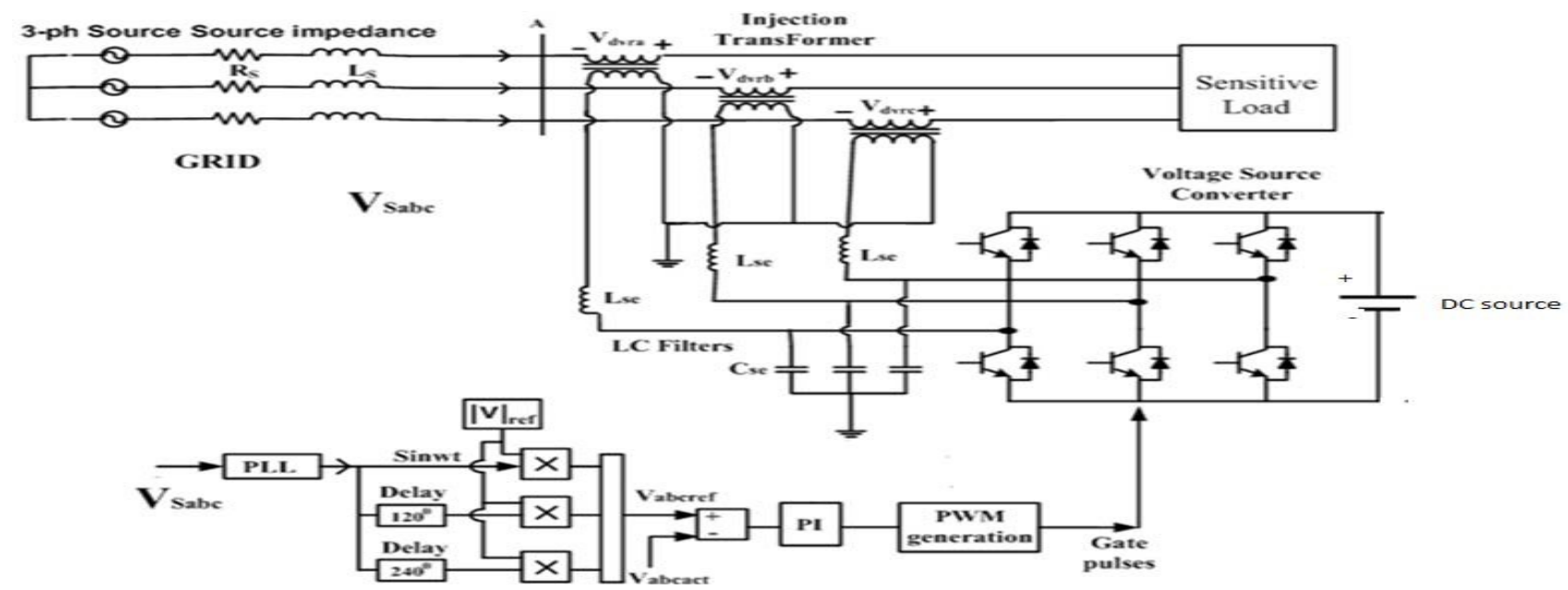

Figure 3: DVR with Simplified PI Based 'abc' frame theory 


\section{MATLAB/SIMULATION RESULTS AND DISCUSSIONS}

The proposed work for voltage quality identification using development of new simplified RMS algorithm is simulated using MATLAB/SIMULATION software. The simulation results are shown in fig.4 to 10 . for different test cases in each phase, two phases and three phases of thesystem.

\section{Case 1: Sag Exists in One Phase of the System}

\begin{tabular}{|l|}
\hline Result \\
\hline Sag Exists In One Phase \\
\hline Sag duration in one phase $=0.09 \mathrm{sec}$ \\
\hline Sag depth in one phase (Per Unit) $=0.49$ \\
\hline
\end{tabular}

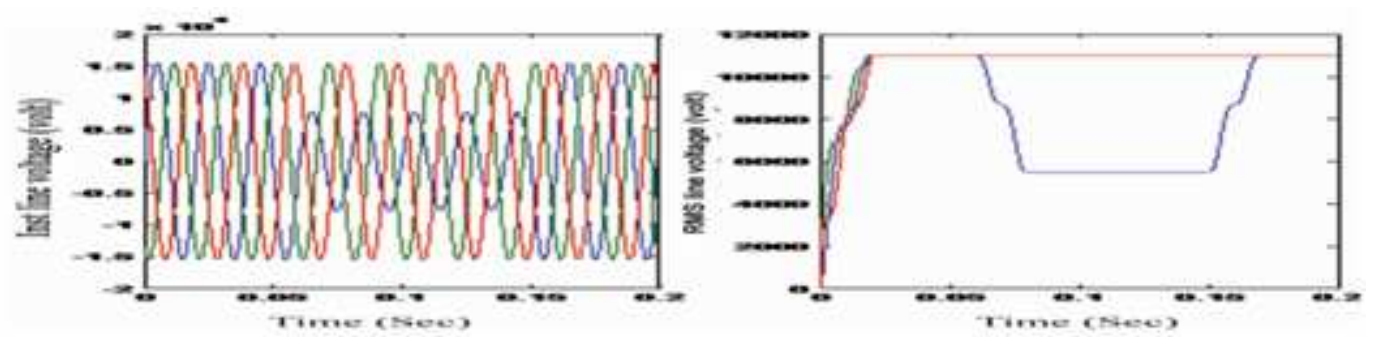

Figure 4: Results showing that sag is present in one phase of the system

Fig.4. shows that the sag exists only in one phase of the system. It is clearly shown in waveform of RMS line voltage. Voltage sag is identified when supply voltage falls below 0.9 p.u for a duration $0.06 \mathrm{sec}$ and continues up to $0.15 \mathrm{sec}$ in phase A. Depth of sag 0.49 pu in phase A. This may be due to a single phase to ground fault also called as L-G fault.

\section{Case 2: Sag Exists in Two Phases of the System}

\begin{tabular}{|l|}
\hline Result \\
\hline Sag Exists In Two Phases \\
\hline Sag Duration In Two Phases $=0.09 \mathrm{sec}$ \\
\hline Sag Depth In Two Phases (Per Unit) =0.49 \\
\hline
\end{tabular}

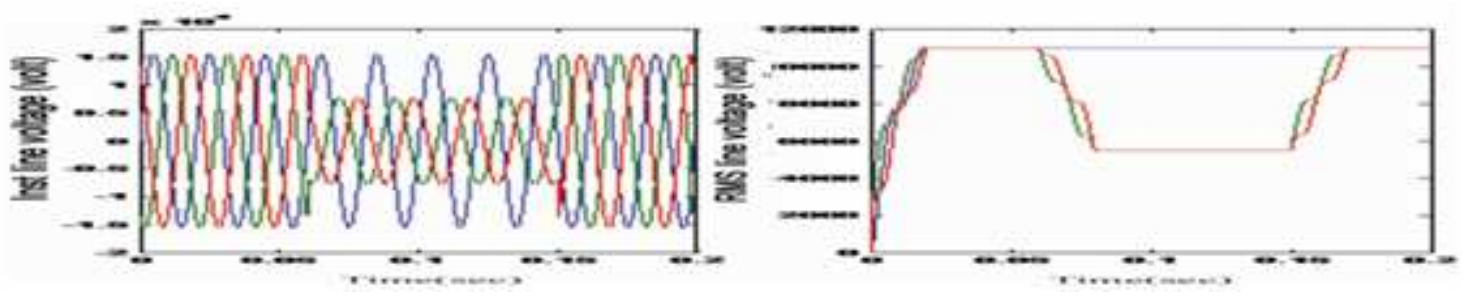

Figure 5: Results show that the sag is present in two phases of the system

Fig.5. shows that the sag is present in two phases of the system. Variations in RMS voltage waveform clearly show that sag occurred in phase A and phase B. Duration of sag period is $0.09 \mathrm{sec}$ and depth of sag is $0.49 \mathrm{pu}$ in phases A and B. This may be due to a fault in two phases of the system ie double line to ground fault also called as LL-G fault.

\section{Case 3: Sag Exists in Three Phases of the System}

\begin{tabular}{|l|}
\hline Result \\
\hline Sag Exists In Three Phases \\
\hline Sag Duration In Three Phases $=0.09 \mathrm{sec}$ \\
\hline Sag Depth In Three Phases (Per Unit) $=0.49$ \\
\hline
\end{tabular}



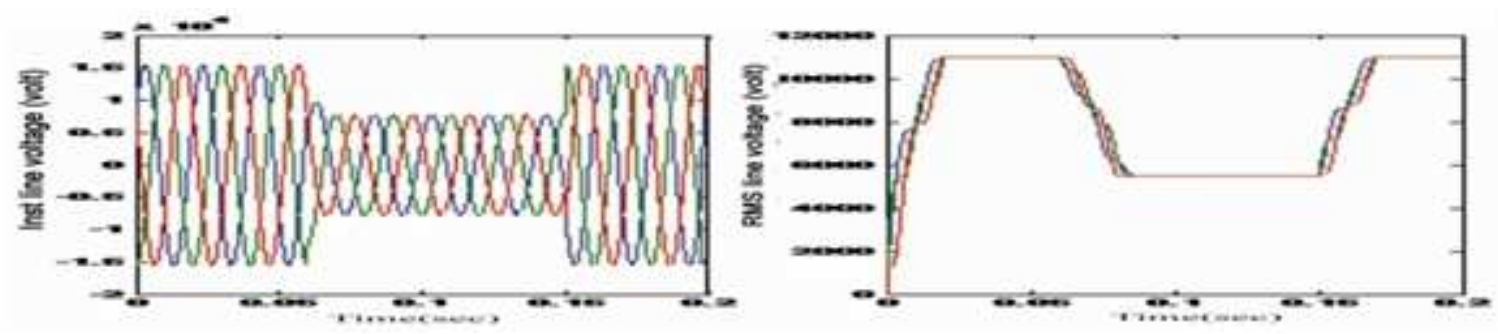

Figure 6: Results show that sag is present in three phases of the system

Fig.6. shows that sag is present in three phases of the system. Variations in waveform clearly show that sag occurs in phases A, B and phase C. This may be due to fault in three phases of the system ie triple line to ground fault also called as LLL- G fault. The duration of sag is $0.09 \mathrm{sec}$ and depth of sag is $0.49 \mathrm{pu}$. This type of fault is very dangerous and can cause high sag in power distributionsystem.

Case 4: Swell Exists in One Phase of the System

\begin{tabular}{|l|}
\hline Result \\
\hline Swell Exists One Phase \\
\hline Swell Duration In One Phase $=0.09 \mathrm{sec}$ \\
\hline Swell Depth In One Phase (Per Unit) $=1.47$ \\
\hline
\end{tabular}

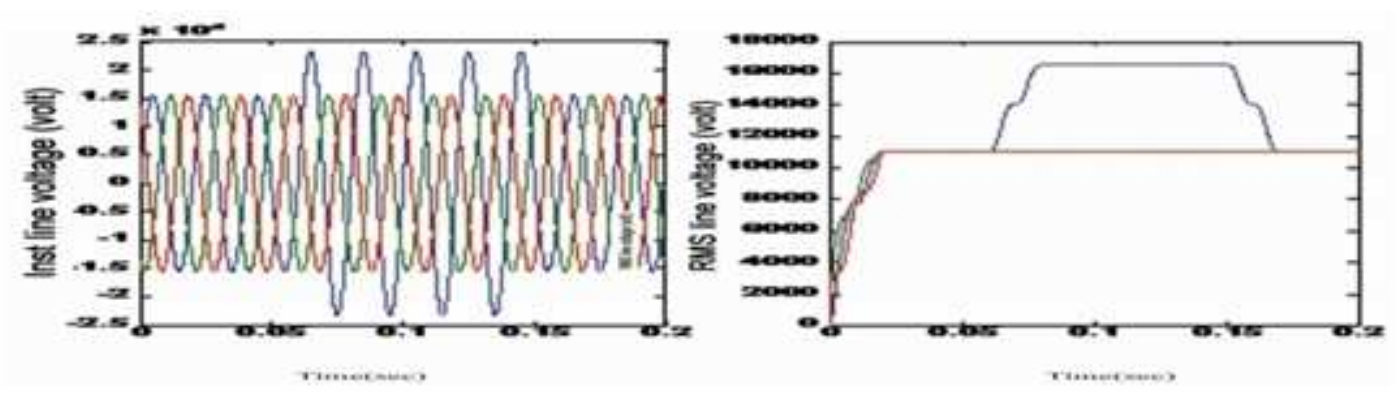

Figure 7: Results showing that swell is present in one phase of the system

Fig.7. shows that the swell is present in one phase of the system. It is clearly show that there is deviation in waveform of the RMS line voltage. Identified magnitude of swell when supply voltage rises above 1.1 p.u for a duration of swell $0.09 \mathrm{sec}$ and depth of swell $1.47 \mathrm{pu}$ in phase A. This type of fault may be occurred due to a fault in single phase to ground also called L-G fault.

Case 5: Swell exists in Two Phases of the System

\begin{tabular}{|l|}
\hline Result \\
\hline Swell Exists In Two Phases \\
\hline Swell Duration In Two Phases $=0.09 \mathrm{sec}$ \\
\hline Swell Depth In Two Phases (Per Unit) = 1.47 \\
\hline
\end{tabular}

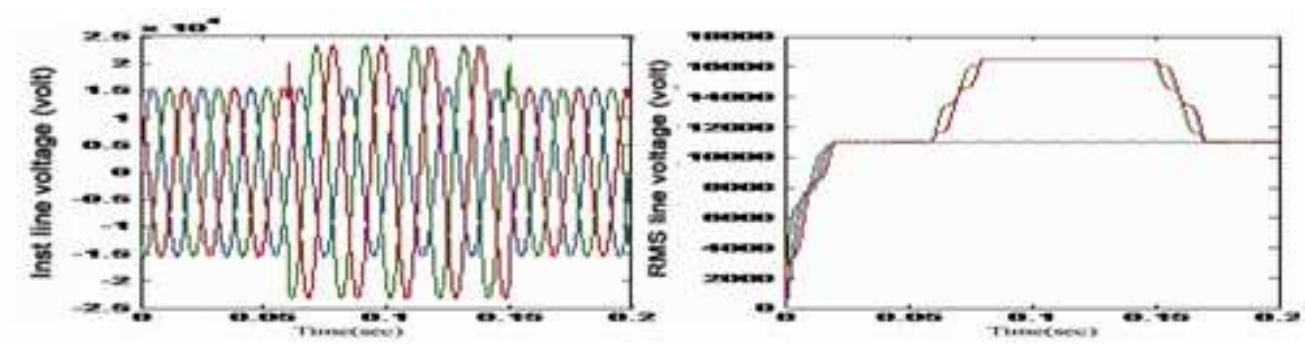

Figure 8: Results showing that swell is present in two phases of the system 
Fig.8. shows that the swell is present in two phase of the system. It is clearly shown that there is deviation in waveform of the RMS line voltage. Magnitude of voltage swell is identified when supply voltage rises above 1.1 pu for a duration of $0.09 \mathrm{sec}$ in phases A and B. Depth of swell 1.47pu in phases A and B.

\section{Case 6: Swell exists in Three Phases of the System}

\begin{tabular}{|l|}
\hline Result \\
\hline Swell Exists In Three Phases \\
\hline Swell Duration In Three Phases $=0.09 \mathrm{sec}$ \\
\hline Swell Depth In Three Phases (Per Unit) $=1.47$ \\
\hline
\end{tabular}

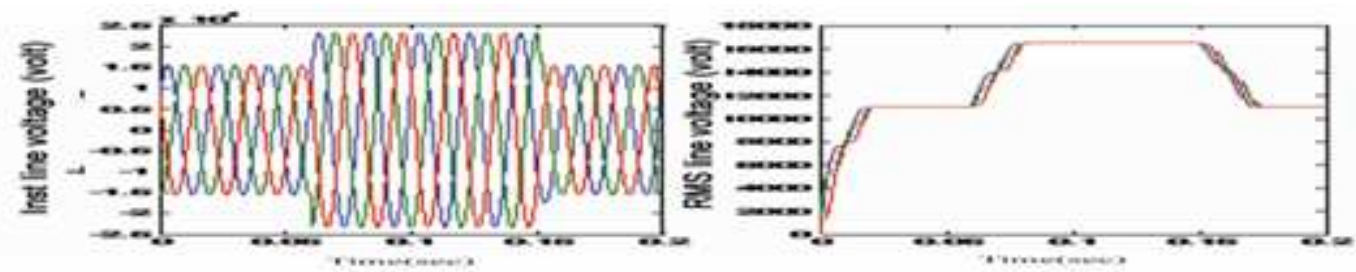

Figure 9: Results showing that swell is present in three phases of the system

Fig.9. shows that the swell is present in three phases of the system. Starting of swell is $0.06 \mathrm{sec}$ and continuous up to $0.15 \mathrm{sec}$ in phases A, B and C. Depth of swell 1.47pu in phases A, B and C. This may be due to switching ON large capacitor banks in power distribution system.

\section{Case 7: Sag and Swell exist in Three Phases of the System}

\begin{tabular}{|l|}
\hline Result \\
\hline Sag Exists In Three Phases \\
\hline Sag Duration In Three Phases $=0.09 \mathrm{sec}$ \\
\hline Sag Depth In Three Phases (Per Unit) $=0.49$ \\
\hline Swell Exists In Three Phases \\
\hline Swell Duration In Three Phases $=0.15 \mathrm{sec}$ \\
\hline Swell Depth In Three Phases (Per Unit) $=1.47$ \\
\hline
\end{tabular}

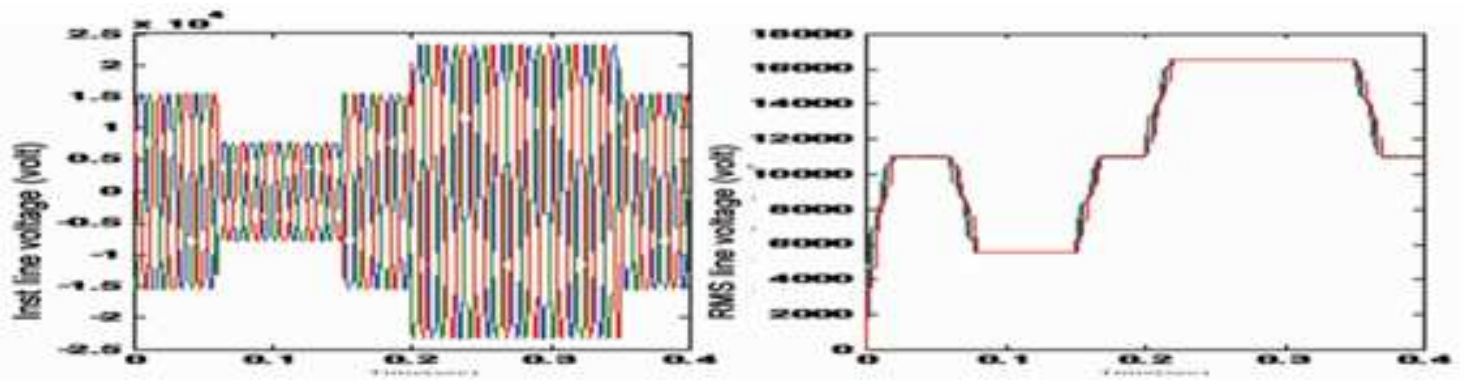

Figure 10: Results showing that sag and swell are present in three phases of the system

Fig.10. shows that the sag and swell are present in three phases of the system. Variations in RMS voltage waveform clearly shown both the sag and swell occurred simultaneously in different durations from $0.06 \mathrm{sec}$ to $0.14 \mathrm{sec}$ and from 0.26 to 0.34 respectively. This type of sag may be due to in three phases to ground also called as LLL-G fault and switching ON large capacitor banks in power distribution system.

Table 1: Identification of Voltage Quality Problem Using Root Mean Square Algorithm

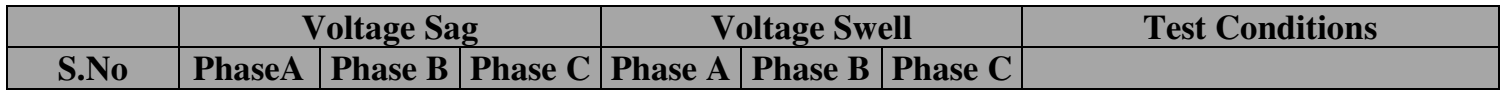




\begin{tabular}{|l|l|l|l|l|l|l|l|}
\hline Case1 & 0 & 0 & 0 & 0 & 0 & 0 & No sag and swell exist \\
\hline Case2 & 1 & 0 & 0 & 0 & 0 & 0 & Sag exists in 1phase \\
\hline Case3 & 0 & 0 & 0 & 1 & 0 & 0 & Swell exists in 1 phase \\
\hline Case4 & 1 & 1 & 0 & 0 & 0 & 0 & Sag exists in 2 phases \\
\hline Case5 & 0 & 0 & 0 & 1 & 1 & 0 & Swell exists in 2 phases \\
\hline Case6 & 1 & 1 & 1 & 0 & 0 & 0 & Sag exists in 3 phases \\
\hline Case7 & 0 & 0 & 0 & 1 & 1 & 1 & Swell exists in 3 phases \\
\hline Case8 & 1 & 0 & 0 & 1 & 0 & 0 & Sag and swell exist in 1 phase \\
\hline Case9 & 1 & 0 & 0 & 1 & 1 & 0 & $\begin{array}{l}\text { Sag exists in 1phase and Swell } \\
\text { exists in 2 phases }\end{array}$ \\
\hline Case10 & 1 & 0 & 0 & 1 & 1 & 1 & $\begin{array}{l}\text { Sag exists in 1phase and Swell } \\
\text { exists in 3 phases }\end{array}$ \\
\hline Case11 & 1 & 1 & 0 & 1 & 0 & 0 & $\begin{array}{l}\text { Sag exists in 2 phases and Swell } \\
\text { exists in 1 phase }\end{array}$ \\
\hline Case12 & 1 & 1 & 0 & 1 & 1 & 0 & \begin{tabular}{l} 
Sag and swell exist in 2 phases \\
\hline Case13
\end{tabular} \\
\hline Case14 & 1 & 1 & 0 & 1 & 1 & 1 & $\begin{array}{l}\text { Sag exists in 2 phases and Swell } \\
\text { exists in 3 phases }\end{array}$ \\
\hline Case15 & 1 & 1 & 1 & 1 & 1 & 0 & $\begin{array}{l}\text { Sag exists in 3 phases and Swell } \\
\text { exists in 1 phase }\end{array}$ \\
\hline Case16 & 1 & 1 & 1 & 1 & 1 & 1 & Sag exists in 3 phases and Swell \\
\hline
\end{tabular}

The test conditions are considered as 1 for ON and 0 for OFF. As shown in above table 2.3 the sag and swell are generated in different phases of the system

The simulation results are shown in figuresto 5.10 for different fault cases. Dynamic voltage restorer handles different fault conditions like single phase fault, two phase fault and three phase fault without any difficulties and injects the suitable voltages to maintain the balanced supply voltages during any of the above faulty situations in order to maintain the nearly balanced load voltage at the nominal value. The DVR has shown the ability to perform mitigation for supply side voltage sag and swell which are proved through MATLAB/SIMULATION.

\section{Case 1: Mitigation of Sag in One Phase of the System}

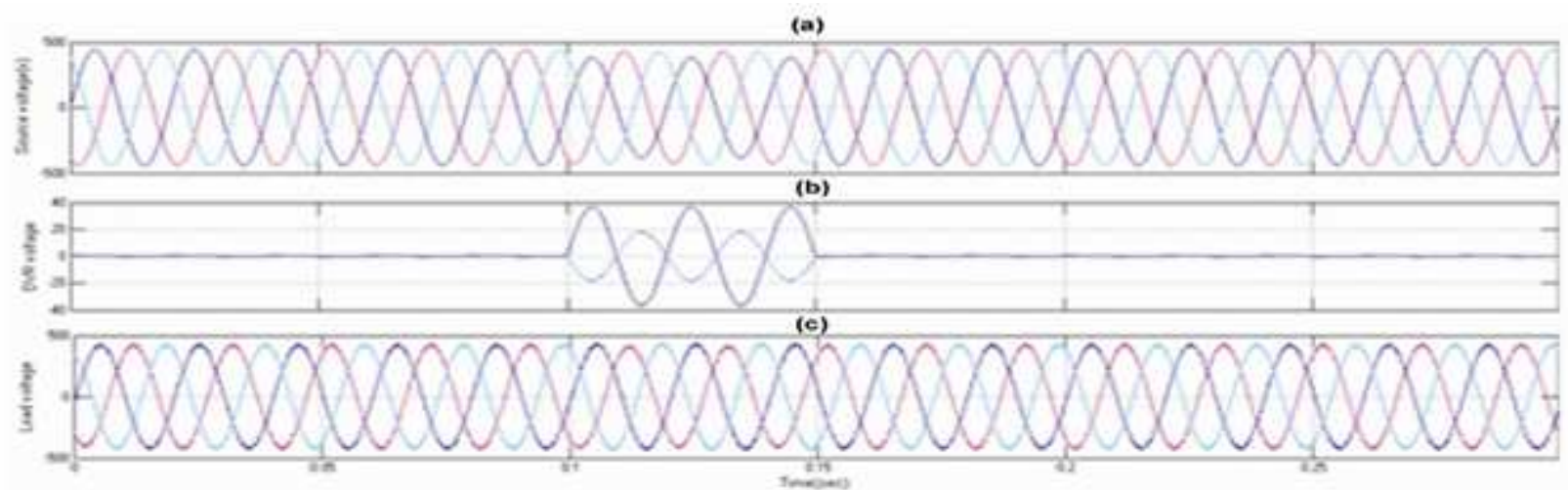

(a)Source Voltage (b) DVR Voltage (c) LoadVoltage

Figure 5.4 Results for one phase sag condition

Matlab/simulation results of the DVR with PI based simple abc algorithm for voltage sag condition of depth $0.68 \mathrm{pu}$ in one phase occurring for a duration from $0.1 \mathrm{sec}$ to $0.15 \mathrm{sec}$ due to (L-G) fault in the system is given in figure 5.4 . Fig.5.4 (a) shows the RMS voltage waveform of the source voltage of the system. Fig.(b) indicates the injected voltage by 
DVR which is nothing but the mitigation voltage. The third waveform (c) denotes the voltage present across sensitive load which is equal to source voltage plus voltage injected by DVR. It is seen that the load voltage is approximately maintained constant byDVR.

\section{Case 2: Mitigation of Sag in Two Phases of the System}

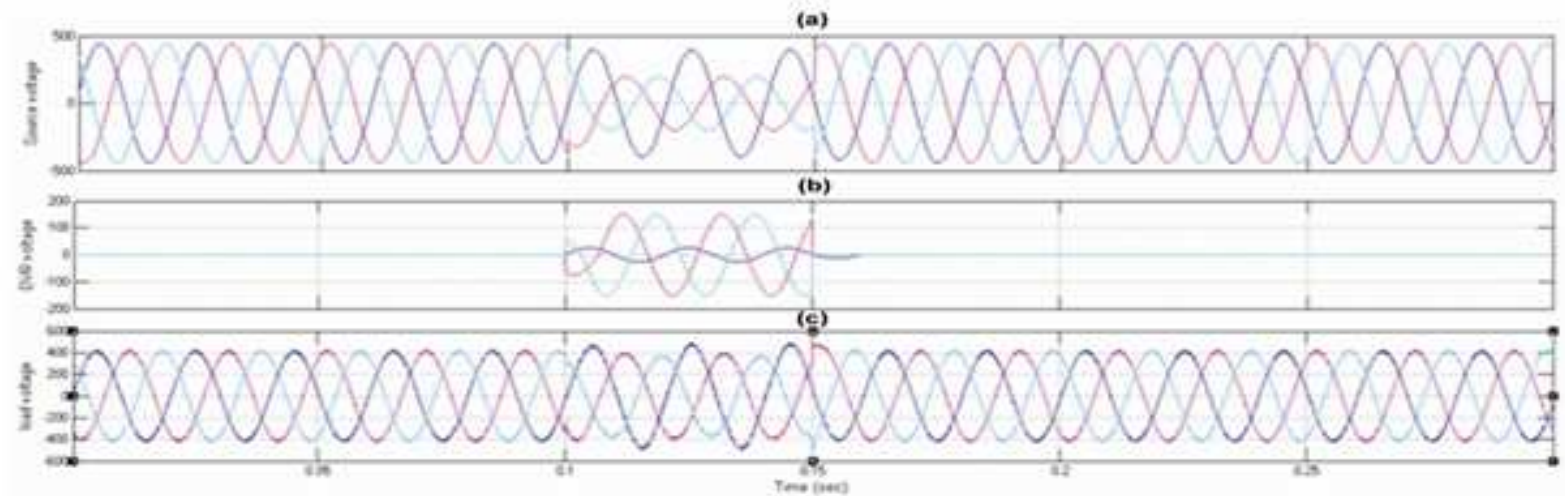

(a) Source Voltage (b) DVR Voltage (c) Load Voltage

Figure 11: Results for two phases sag condition

Matlab/simulation results of the DVR with PI based simple abc algorithm for voltage sag condition of depth $0.45 \mathrm{pu}$ in two phases occurring for a duration from $0.1 \mathrm{sec}$ to $0.15 \mathrm{sec}$ due to (LL-G) fault in the system is given in figure 11. Fig.11. (a) shows the RMS voltage waveform of the source voltage of the system. Fig,(b) indicates the injected voltage by DVR which is nothing but the mitigation voltage. The third waveform (c) denotes the voltage present across sensitive load which is equal to source voltage plus voltage injected by DVR. It is seen that the DVR nearly mitigates the loadvoltage.

\section{Case 3: Mitigation of Sag in Three Phases of the System}

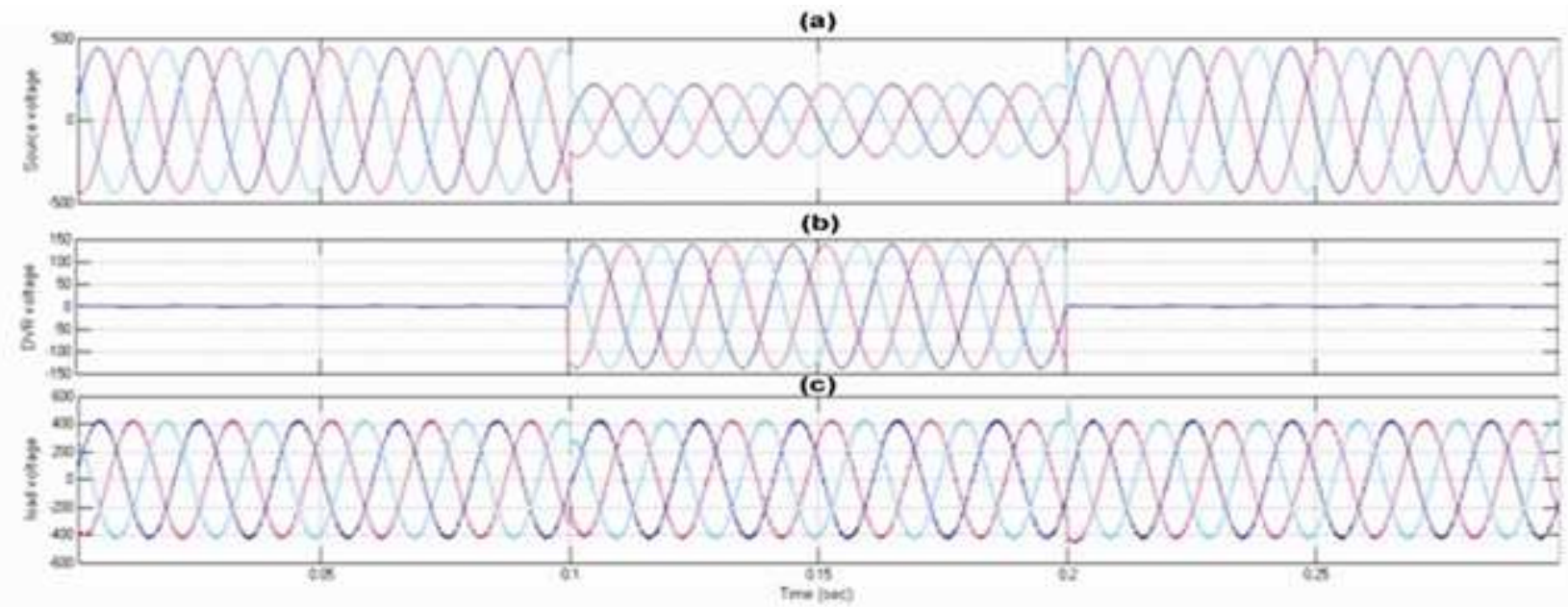

(a) Source Voltage (b) DVR Voltage (c) Load Voltage

Figure 12: Results for three phases sag condition

Matlab/simulation results of the DVR with PI based simple abc algorithm for voltage sag condition of depth $0.45 \mathrm{pu}$ in three phases occurring for a duration from $0.1 \mathrm{sec}$ to $0.2 \mathrm{sec}$ due to (LLL-G) fault in the system is given in figure 
12. Fig.12 (a) shows the RMS voltage waveform of the source voltage of the system. Fig,(b) indicates the injected voltage by DVR which is nothing but the mitigation voltage. The third waveform (c) denotes the voltage present across sensitive load which is equal to source voltage plus voltage injected by DVR. It is seen that the load voltage is nearly maintained constant byDVR.

\section{Case 4: Mitigation of Swell in One Phase of the System}

\section{Figure 13: Results for one phase swell condition}

\section{(a) Source Voltage (b) DVR Voltage (c) Load Voltage}

Matlab/simulation results of the DVR with PI based simple abc algorithm for voltage swell condition of depth 1.13pu in one phase occurring for a duration from $0.1 \mathrm{sec}$ to $0.15 \mathrm{sec}$ due to switching ON large capacitor banks in the system is given in fig.13. Fig. 13 (a) shows RMS voltage waveform of the source voltage of the system. Fig.(b) indicates absorbed voltage by DVR which is nothing but the mitigation voltage. The fig.(c) denotes the voltage present across sensitive load. It is seen that the DVR nearly mitigates the load voltage.

\section{Case 5: Mitigation of Swell in Two Phases of the System}

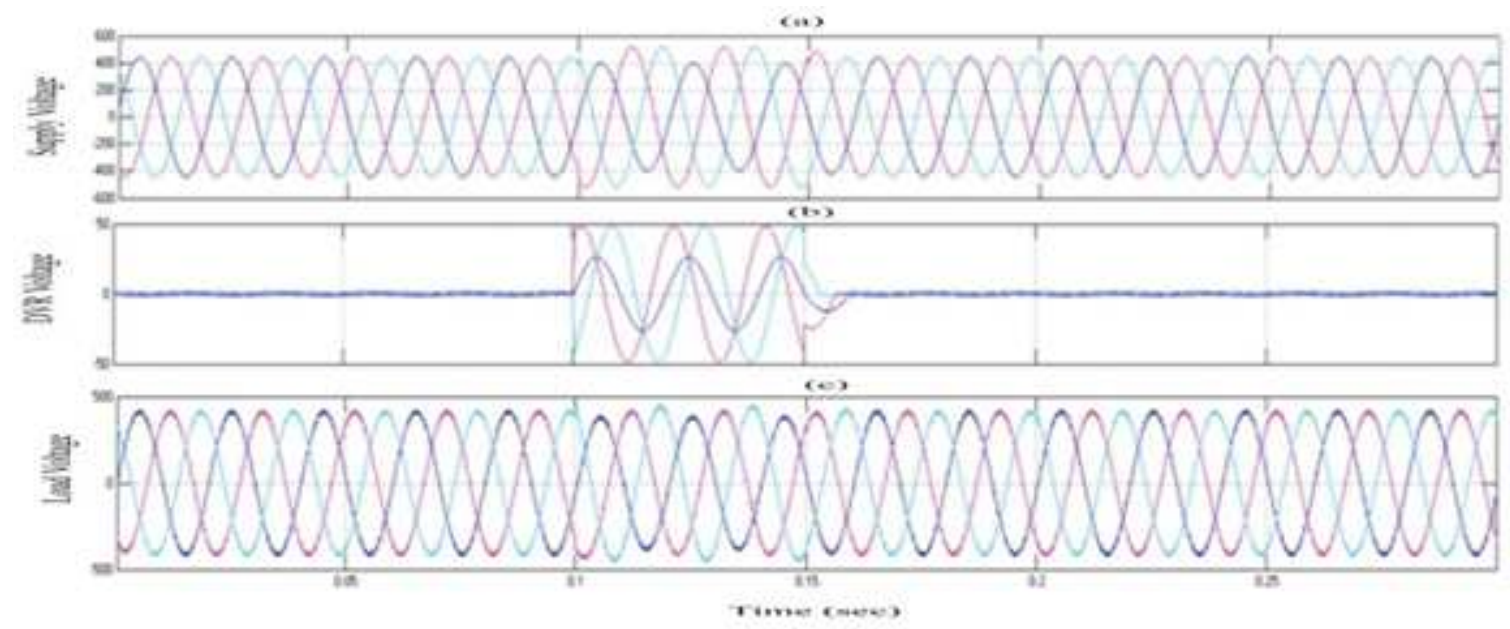

(a)Source Voltage (b) DVR Voltage (c) Load Voltage

Figure 14: Results for Results for two phases swell condition

Matlab/simulation results of the DVR with PI based simple abc algorithm for voltage swell condition of depth $1.13 \mathrm{pu}$ in two phases occurring for a duration from $0.1 \mathrm{sec}$ to $0.15 \mathrm{sec}$ due to switching ON large capacitor banks in the system is given in fig.14.. Fig. 14. (a) shows RMS voltage waveform of the source voltage of the system. Fig.(b) indicates absorbed voltage by DVR which is nothing but the mitigation voltage. The third waveform (c) denotes the voltage present across sensitive load. It is seen that the load voltage is closely maintained constant by DVR. 


\section{Case 6: Mitigation of Swell in Three Phases of the System}

(a)

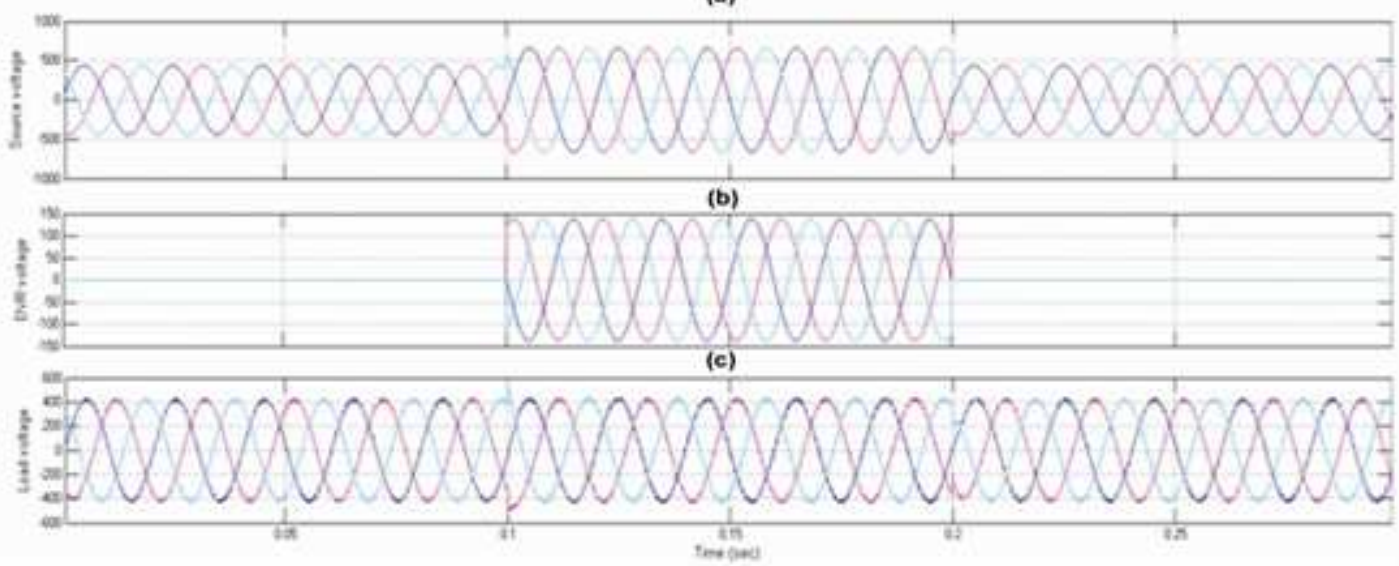

(a) Source Voltage (b) DVR Voltage (c) Load Voltage

Figure 15: Results for Results for three phases swell condition

The Matlab/simulation results of the DVR with PI based simple abc algorithm for voltage swell condition of depth $1.42 \mathrm{pu}$ in three phases occurring for a duration from $0.1 \mathrm{sec}$ to $0.2 \mathrm{sec}$ due to switching ON large capacitor banks in the system is given in fig.15. Fig. 15 (a) shows RMS voltage waveform of the source voltage of the system. Fig.(b) indicates absorbed voltage by DVR which is nothing but the mitigation voltage. The fig.(c) denotes the voltage present across sensitive load. It is seen that the load voltage is nearly maintained constant byDVR.

Case 7: Mitigation of Sag and Swell in Three Phases of the System

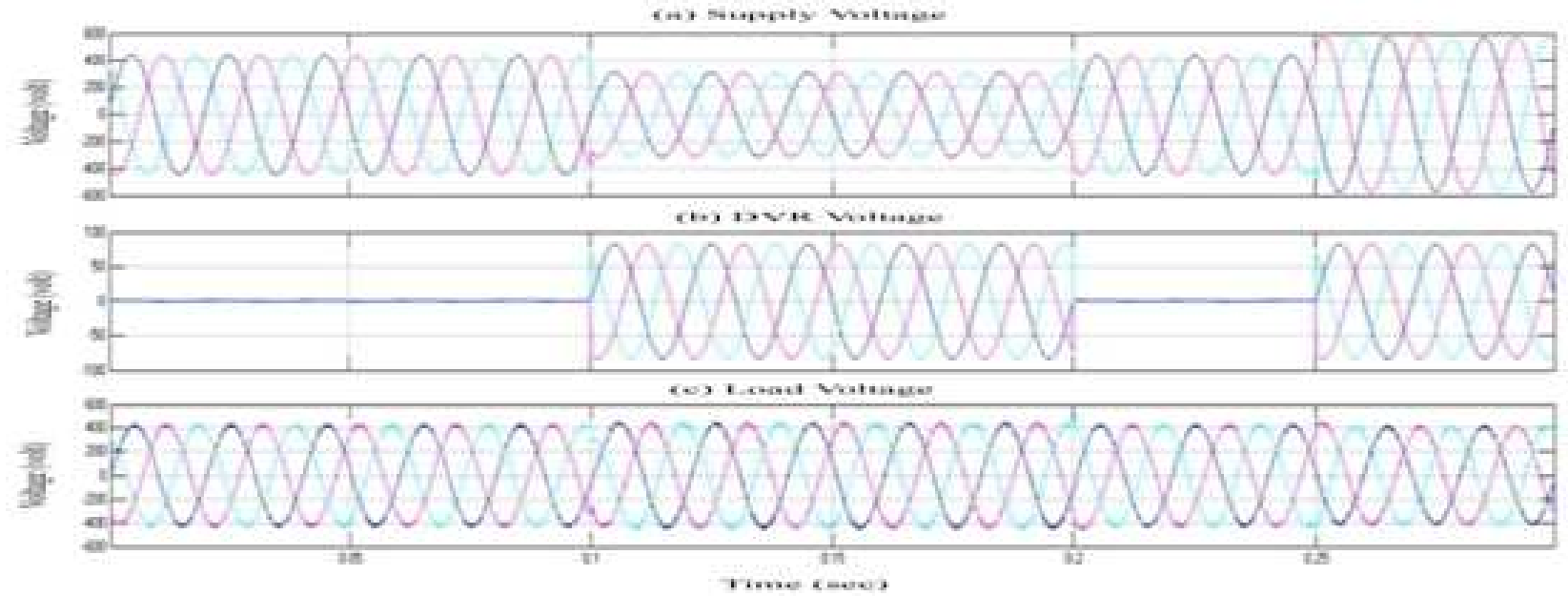

(a) Source Voltage (b) DVR Voltage (c) Load Voltage

Figure 16: Results for three phases sag and swell condition

Matlab/simulation results of the DVR with PI based simple abc algorithm for voltage sag and swell condition of depth 0.68 and $1.13 \mathrm{pu}$ in three phases occurring for a duration from $0.1 \mathrm{sec}$ to $0.2 \mathrm{sec}$ and 0.25 to $0.3 \mathrm{sec}$ due to (LLL-G) and switching ON large capacitor banks respectively in the system is given in fig.16. Fig. 16 (a) shows RMS voltage waveform of the source voltage of the system. Fig.(b) indicates injected and absorbed voltage by DVR which is nothing but the compensation voltage. The fig.(c) denotes the voltage present across sensitive load. It is seen that the DVR nearly mitigates 
the load voltage.

\section{CONCLUSIONS}

The proposed Root Mean Square (RMS) algorithm is used for identification of voltage sag and swell. The scheme does not make use of any conversion of true rms of the voltage signal. The algorithm is very simple to identify voltage quality issues like sag and swell in different cases. The results are obtained using Matlab/Simulink shown in figures 4 to 10 and test results are shown in Table1. After identification it is necessary to provide suitable solutions for mitigation of voltage quality disturbances using suitable devices.

In this Paper, performance of simplified PI based abc controller for DVR is illustrated in detail. The scheme does not make use of any transformation of abc equations. The gains of PI controller $\left(\mathrm{k}_{\mathrm{p}}=10\right)$ and $\left(\mathrm{k}_{\mathrm{i}}=1\right)$ are found by trial and error method. The simple abc control algorithm based DVR with PI scheme provides less operating time, low available cost and smaller in size compared to SRF. The simulation is carried out using MATLAB/SIMULINK software and simulation diagram is presented in fig.5.3. The simulation results are shown in figures 11 to 16 for different fault cases. The DVR has shown the ability to perform mitigation for supply side disturbances like voltage sag/ swell, multiple sag and swell which are proved throughMATLAB/SIMULATION.

\section{REFERENCES}

1. Suresh Kamble and Dr.ChandrashekhraThorat, "A New method for Voltage Sag Detection" IEEE International Conference on Advances in Engineering, Science and Management (ICAESM -2012) March2012

2. C.Mestres," Computer Power Supply, analysis of service quality in voltage dips field." Revue journal of electrical power supply81(9):531-6

3. F.Tosato and G.Giadrossi, et al."The problems posed by voltage supply dips to industrial power electronic loads", 6th Mediterranean Conference Electro technical Proceedings (Cat.No.91CH2964- 5),22-24 May1991,Slovenia,IEEE

4. Eashwaramma, N., J. Praveen, and M. Vijayakumar. "Modelling and Designing of Cascaded 9 Level Voltage Source Converter Based on DVR for Mitigating Harmonics in Distributed Power System Using Unit Vector." International Journal of Electrical and Electronics Engineering Research (IJEEER) 8.1 (2018): 11-20.

5. L. Cristaldi, A. Ferrero, and S. Salicone, -A distributed system for electric power quality measurement, $\|$ inProc. 18th IEEE Instrumentation and Measurement Technology Conf., Budapest, Hungary, 2001, vol. 3, pp. 2130-2135.

6. H. J. Bollen, Understanding Power Quality Problems: Voltage Sags and Interruptions. New York: IEEE Press, 1999

7. U. T. Patil; A. R. Thorat; "Hysteresis Voltage Control Technique in Dynamic Voltage Restorer for Power Quality Improvement" 978-1-4673-6150-7/13/\$31.00 @2013 IEEE.

8. Ali, SYED YASSER, and K. Suneeta. "Simulation of the hysteresis voltage control technique in the pv based dynamic voltage restorer for power quality improvement with induction motor drive." International Journal of Electrical and Electronics Engineering Research (IJEEER) 5.1 (2015): 95-106.

9. Lim PK, Dor DS. Understanding and resolving voltage sag related problems for sensitive industrial customers. IEEE Power EngSoc Winter Meet 20011;4:2886-90.

10. Prakash, Y.; Sankar, S, Power Quality Improvement Using DVR in Power System, Power and Energy Systems: Towards Sustainable Energy (PESTSE 2014) 
11. Y. W. Li, D. M. Vilathgamuwa, F. Blaabjerg, and P. C. Loh, "A robust control scheme for medium-voltage-level DVR implementation," IEEE Trans. Ind. Electron., vol. 54, no. 4, pp. 2249-2261, Aug. 2007.

12. HA, P. ANUS, and K. SWARNASRI. "A NOVEL APPROACH TO COMPENSATE VOLTAGE SAG IN THREE PHASE LINES."International Journal of Electrical and Electronics Engineering Research (IJEEER) 4. 2, Apr 2014, 229-238

A. K. Sadigh and K. M. Smedley, "Review of voltage compensation methods in dynamic voltage restorer (DVR)," in Proc. IEEE Power Energy Soc. Gen. Meet., Jul. 2012, pp. 1-8

13. Dr. T. Ruben; Deva Prakash; G.Justin; Sunil Dhas; "A Novel approach for Voltage Sag Mitigation Using FACTS Device Interline Dynamic Voltage Restorer"978-1-4244-8679- 3/11/\$26.00@2011IEEE"

14. Venkateswarlu, G., M. Pavan, and P. Raju. "Improvement Of The Voltage Stability In The Distribution System By Using The Multifunctional Dynamic Voltage Restorer." International Journal of Electrical and Electronics Engineering (IJEEE) 3.1 (2014): 37-48.

A. Y. Goharrizi, S. H. Hosseini, M. Sabahi, and G. B. Gharehpetian, "Three-phase HFL-DVR with independently controlled phases," IEEE Trans. Power Electron., vol. 27, no. 4, pp. 1706-1718, Apr. 2012.

15. S. Muqthiar Ali, P. B. Chennaiah, S. Arifulla "Compensate Voltage Sags in Series Transformers of Dynamic Voltage Restorers for Preventing Saturation” IJST Volume 8, Issue 30, November 2015

16. Mohanasundaram Ravi "Comparison of PV Supported DVR and DSTATCOM with Multiple Feeders in Stand Alone WECS by Mitigating Power Quality Problems" IJST Volume 8, Issue 30, November 2015 

